\title{
Structure determination and composite wing spar stress-strain state estimation
}

\author{
Pavel Solovyev ${ }^{1}$, Andrey Gomzin ${ }^{1, *}$, Yuriy Pervushin ${ }^{2}$, Fanil Musin $^{1}$, and Sergey Galyshew ${ }^{1}$ \\ ${ }^{1}$ FSBEE USATU, Department of Materials Science and Physics of Metals, 450008, Ufa, Russia \\ ${ }^{2}$ FSBEE USATU, Department of Materials Resistance, 450008, Ufa, Russia
}

\begin{abstract}
The paper presents the results of studies on the stress-strain state of composite wing spars with different lay-up structures. The object of research is a U-shaped cross-section composite wing spar. On the basis of the analysis of the stress-strain state, the most favorable structure of a wing spar from the viewpoint of minimizing the risk of stress state and providing the highest stiffness. Recommendations are given on layup structure stacking (compared with typical structures) for more effective perception of external loads by a wing spar.
\end{abstract}

\section{Introduction}

Currently there is a clear tendency in the world practice of aircraft building to increase the share of composite materials in airframes construction. This tendency is due to the fact that composite materials have the best set of physical and mechanical properties, especially high specific strength and stiffness characteristics, high longterm strength, low sensitivity to stress concentrators. Extension of application areas of composites is conditioned by their introduction in design of airframe load-bearing elements.

Use of composite materials in load-bearing airplane elements (Fig. 1.b) allows making a fuselage and wings (Fig. 1.a) not only light and strong, but also to decrease assembly time by reducing the number of assembly units, while increasing reliability of a design.

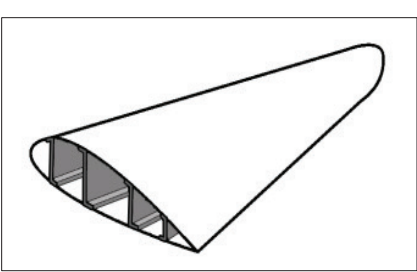

(a)

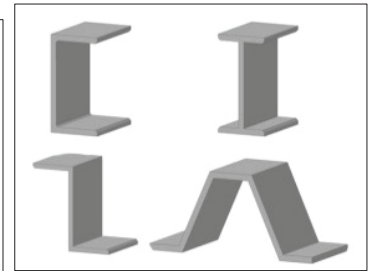

(b)
Fig. 1. Cross-section of an aircraft wing with a longitudinal set of wing spars (a) and several profiles types of airframe loadbearing elements (b).

A significant feature of composite materials is the ability to vary a composite structure to obtain the highest properties in those directions in which a product is exposed to maximum loads. However, calculation of composite materials products is a complicated and laborious problem.

The solution of a similar problem could be significantly simplified, if there were reference databases on the variants of composite materials structures, depending on the purpose of a load-bearing element and loads acting on it.

In practice, usually the following typical structures are used in composite structures: unidirectional (Fig. 2.a); bidirectional (Fig. 2.b); three-layer structure (Fig. 2.c); quasi-isotropic structure (Fig. 2.d).

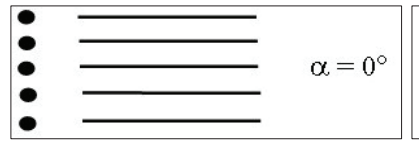

(a)

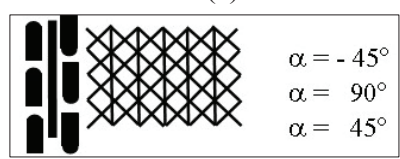

(c)

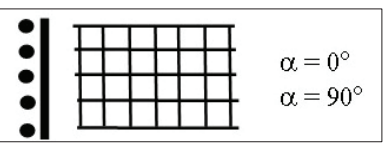

(b)

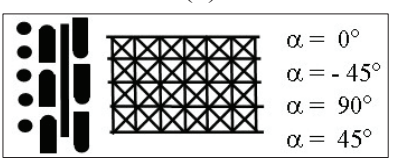

(d)
Fig. 2. Typical lay-up structures for products from composite materials.

For example, in certain world scientific sources [1] the opinion prevails that it is most convenient to design laminated composites using layered cells. These cells consist of several layers oriented at no more than four different angles and repeated the required number of times to reach a needed thickness of composite. However, this approach does not allow designers to obtain maximum efficiency of those composites.

So, the major disadvantage of such typical structures is that they do not take into account individual loading features of specific elements.

Therefore, typical structures are rarely used for multiload products, as a rule, without making any changes.

All of the above-mentioned makes it urgent to determine typical and individual structures of major loadbearing elements of an aircraft (spars, stringers, ribs,

\footnotetext{
* Corresponding author: andre-gomzi@yandex.ru
} 
frames), that provide favorable perception of an external load field.

\section{Research goals and objectives}

The purpose of this research is to establish the patterns for choosing basic typical composite structures for the design and manufacture of aircraft fuselage load-bearing elements, depending on their stress-strain state. To achieve this goal, the following tasks are solved in this study:

1. Analysis of the stress-strain state of a spar with a Ushaped section;

2. Choice of a typical layer stacking structure of a spar made from composite material, providing a favorable stress state and deformation behavior;

3. Practical recommendations on the choice of rational structures for aircraft load-bearing elements.

\section{Computing experiment}

A spar with a U-shaped cross-section is chosen to perform this experiment. The real force factors acting on the spar element are shown in Fig. 3.

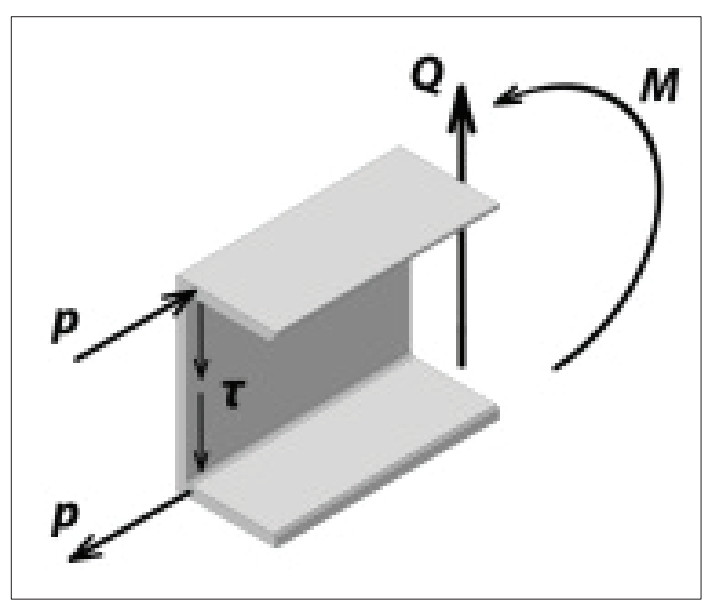

Fig. 3. Spar loading scheme.

The spar flanges operate in the tension/compression mode induced by the bending moment, and the spar web takes up shearing forces.

\subsection{Initial data}

The modeled spar material in this research is carbon fiber reinforced plastic based on a carbon ribbon and a polyimide matrix.

Carbon ribbon: density $\rho=1.7 \mathrm{~g} / \mathrm{cm}^{3}$; tensile strength $\bar{\sigma}_{\mathrm{B} 1}^{+}=2750 \mathrm{MPa}$; elastic modulus along fibers $E_{\mathrm{B} 1}=210$ $\mathrm{GPa}$; elastic modulus across fibers $E_{\mathrm{B} 2}=8 \mathrm{MPa}$, Poisson ratio $v_{\mathrm{B} 12}=0,15$.

Polyimide matrix: density $\rho=1.2 \mathrm{~g} / \mathrm{cm}^{3}$; tensile strength $\bar{\sigma}_{\mathrm{M}}^{+}=114 \mathrm{MPa}$; elastic modulus $E_{\mathrm{M}}=4.2 \mathrm{GPa}$; Poisson ratio $v_{\mathrm{M}}=0.3$.
The physical and mechanical characteristics of the composite unidirectional layer are calculated by the method considered in $[2,3]$ and are presented below.

The unidirectional composite elastic characteristics at the standard temperature $\mathrm{t}=20^{\circ} \mathrm{C}: E_{11}=127.7 \mathrm{GPa} ; E_{22}$ $=6.2 \mathrm{GPa} ; E_{33}=6.2 \mathrm{GPa} ; G_{12}=4.3 \mathrm{GPa} ; G_{13}=4.3 \mathrm{GPa}$; $G_{23}=1.56 \mathrm{GPa} ; v_{12}=0.226 ; \rho=1.5 \mathrm{~g} / \mathrm{cm}^{3}$.

The unidirectional composite strength characteristics at the standard temperature $\mathrm{t}=20^{\circ} \mathrm{C}: \bar{\sigma}_{11 \mathrm{p}}=1.4 \mathrm{GPa} ; \bar{\sigma}_{11 \mathrm{c}}=$ $0.95 \mathrm{GPa} ; \bar{\sigma}_{22 \mathrm{p}}=93.1 \mathrm{MPa} ; \bar{\sigma}_{22 \mathrm{c}}=93.1 \mathrm{MPa} ; \bar{\tau}_{12}=52.4$ $\mathrm{MPa}$.

The geometrical parameters of a spar: height $h=100$ $\mathrm{mm}$, width $b=40 \mathrm{~mm}$, length $l=1 \mathrm{~m}$.

The initial layers stacking structure of the composite spar is $\left(0^{\circ}\right)_{n}$. The direction of the main coordinate system is along the longitudinal axis of the spar. The number of layers is $n=13$. The thickness of one layer is $h_{c}=2 \mathrm{~mm}$.

The boundary conditions: fixed support on one of the tips, pressure $\mathrm{p}=10 \mathrm{kPa}$, uniformly distributed over the lower flange of the spar. These boundary conditions are chosen on the basis of the analysis of force factors acting on the real wing spars of an aircraft.

\subsection{Simulation of loading of the unidirectional structure spar}

The composite spar is simulated in the ANSYS software using the ANSYS Composite Prepost module. The number of model elements is about 26,000.

Figure 4 displays the spar deformation caused by the above-mentioned force factors. The figure shows that under the bending loads, the spar not only bends, but also twists.

Figure 5 shows the distribution of the safety factor for the composite spar.

The RF safety factor is determined in accordance with the selected strength criterion - in this case the Mises-Hill criterion, which is widely used to assess the risk of the stressed state in the layers of the composite material during the ply strength analysis [4,5] - using the formula:

$$
\begin{aligned}
& R F=(I R F)^{-1}=\left(\sqrt{H_{c r}}\right)^{-1}= \\
& =\left(\sqrt{\left(\frac{\sigma_{1}}{X}\right)^{2}-\frac{\sigma_{1} \sigma_{2}}{X Y}+\left(\frac{\sigma_{2}}{Y}\right)^{2}+\left(\frac{\tau_{12}}{S}\right)^{2}}\right)^{-1}
\end{aligned}
$$

where $X, Y$ и $S$-the ultimate stresses in the conditions of uniaxial loading of the unidirectional layer in the direction parallel and perpendicular to the fibers and under the shear in the plane of the layer, respectively, $\sigma_{1}, \sigma_{2}, \tau_{12}-$ the acting stresses in the direction of the principal axes of elasticity of the unidirectional layer.

The graph demonstrates that the minimum value of the safety factor is determined in the most loaded element and is equal to $R F_{\min }=11.06$. In general, the spar strength is ensured for the given loads. 


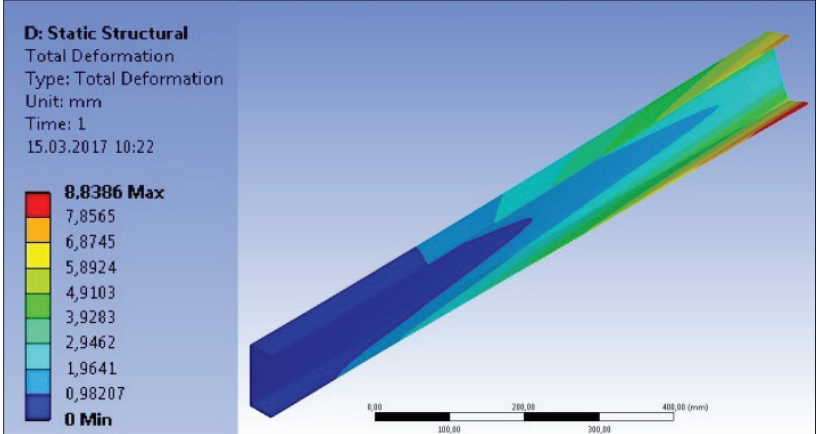

(a)

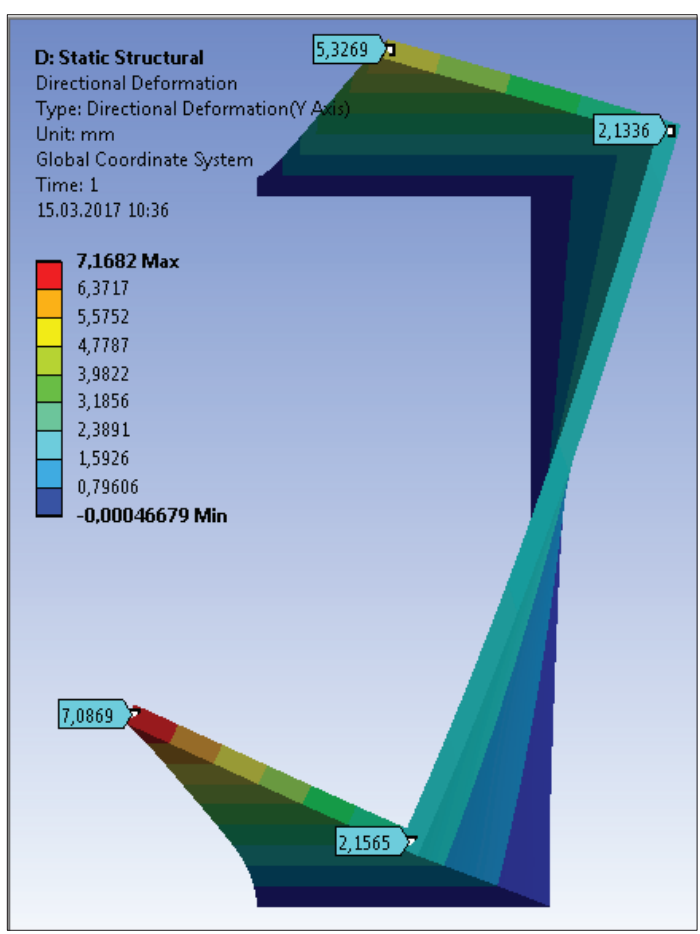

(b)

Fig. 4. Deformation of the spar under the action of specified loads

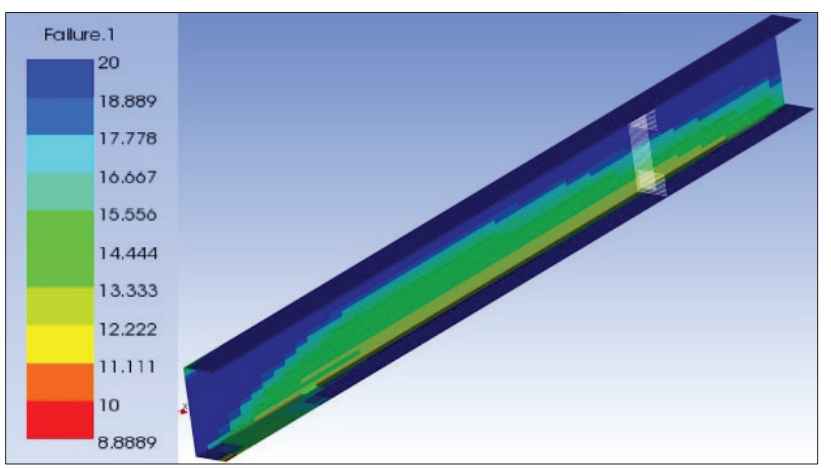

Fig. 5. Distribution of the safety factor for the composite spar

By analyzing the distribution of the reserve factors, one can conclude that the most loaded are the outer layers with numbers №1 and №13.

Figures 6-11 show the stresses in two outer layers of the spar oriented at an angle $0^{\circ}$. The green arrows in the figures show the directions of fiber orientation.

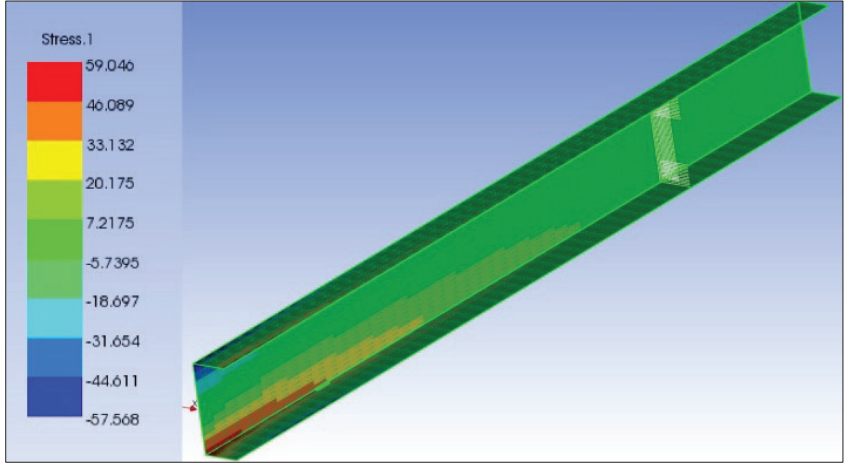

Fig. 6. Distribution of normal stresses (along fibers) $\sigma_{1}$ in the spar layer №1 oriented at an angle $0^{\circ}$ (MPa).

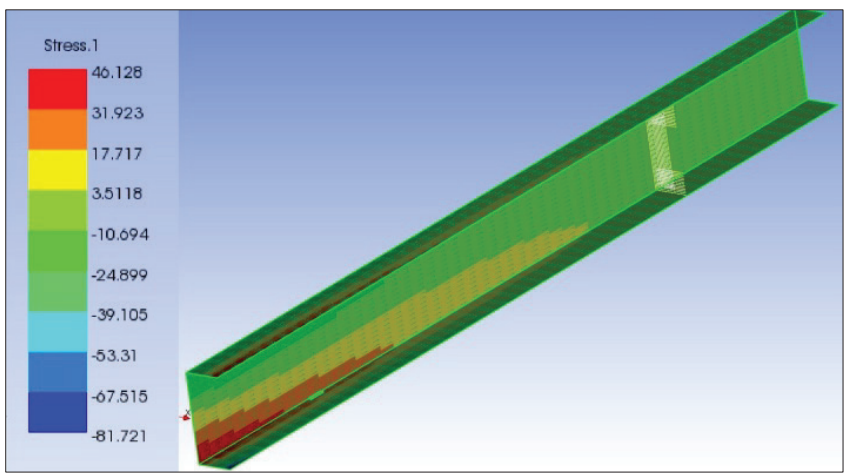

Fig. 7. Distribution of normal stresses (along fibers) $\sigma_{1}$ in the spar layer № 13 oriented at an angle $0^{\circ}(\mathrm{MPa})$.

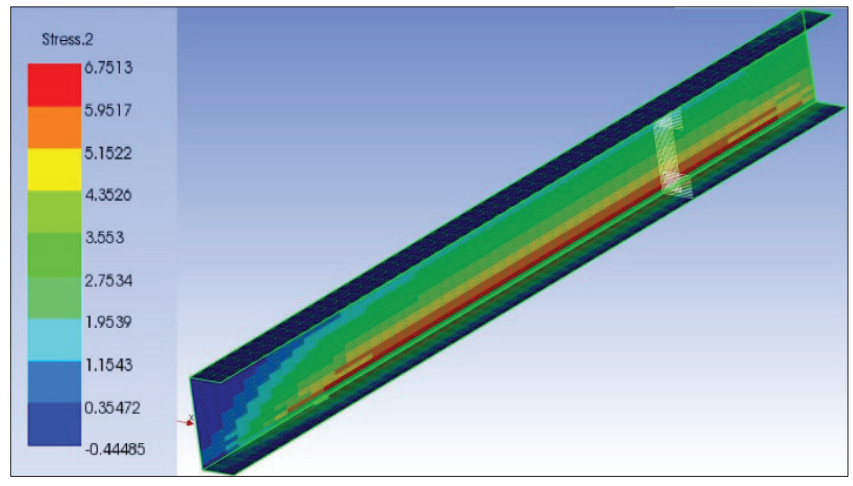

Fig. 8. Distribution of normal stresses (across fibers) $\sigma_{2}$ in the spar layer №1 oriented at an angle $0^{\circ}$ (MPa).

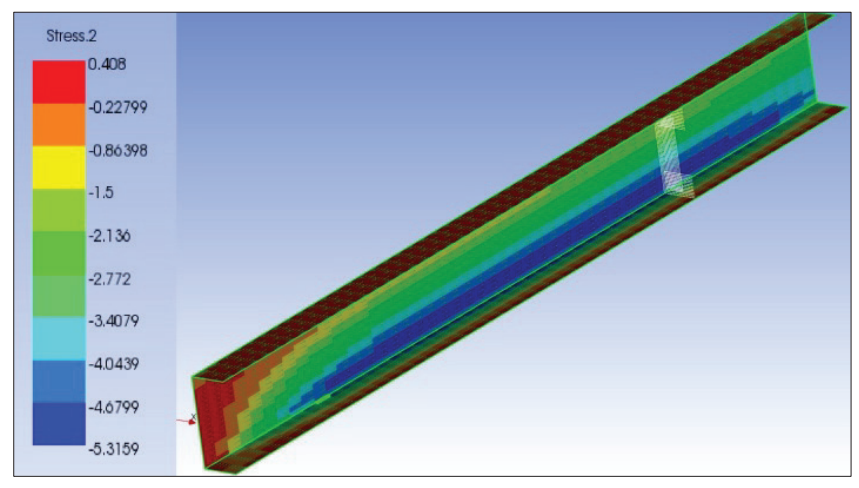

Fig. 9. Distribution of normal stresses (across fibers) $\sigma_{2}$ in the spar layer №13 oriented at an angle $0^{\circ}(\mathrm{MPa})$. 


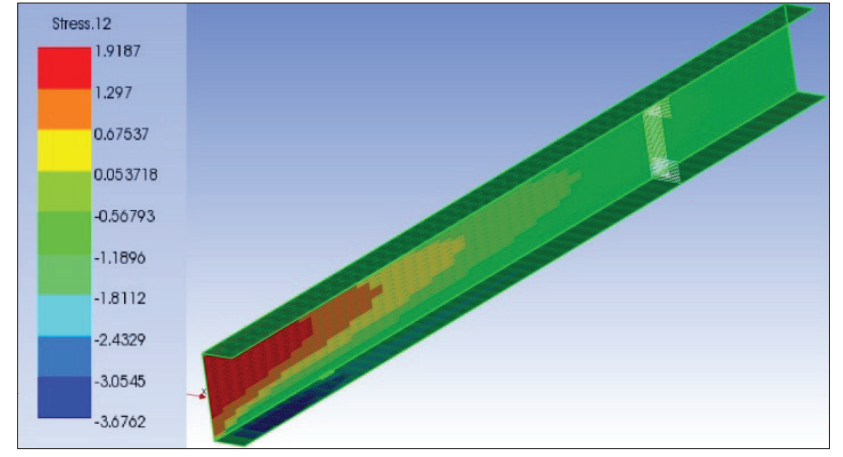

Fig. 10. Distribution of shear stresses in ply plane $\tau_{12}$ in the spar layer №1 oriented at an angle $0^{\circ}(\mathrm{MPa})$.

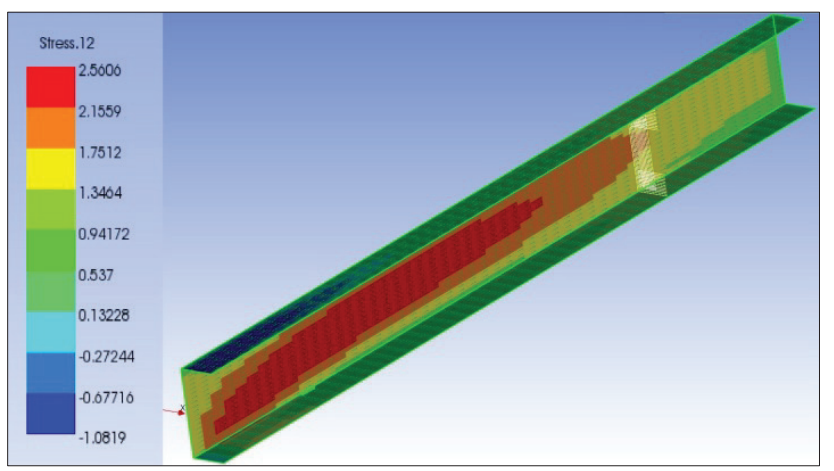

Fig. 11. Distribution of shear stresses in ply plane $\tau_{12}$ in the spar layer №13 oriented at an angle $0^{\circ}$ (MPa).

Fig. 12 displays the distribution of stresses and safety factors in the most loaded element over all layers and the distribution of the elastic properties of the layered element as a function of direction.

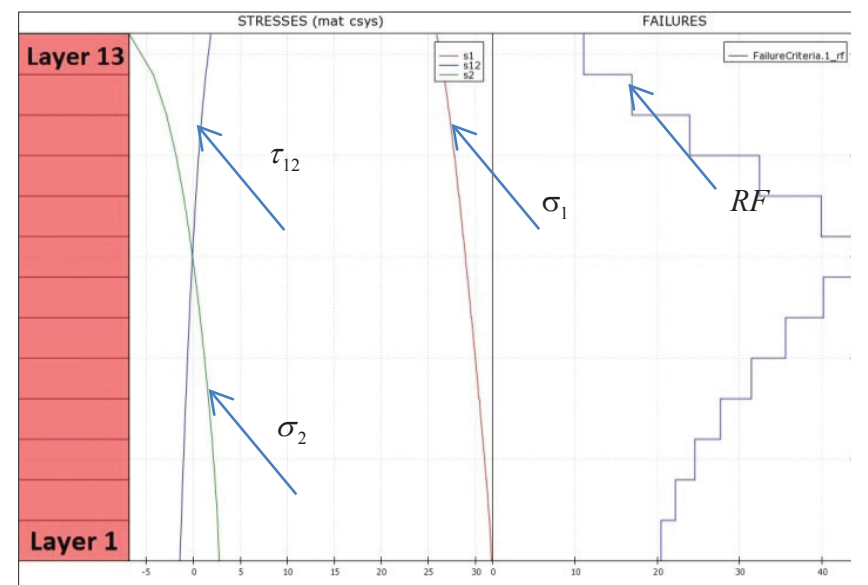

Fig. 12. Distribution of stresses, safety factors and elastic properties in the most loaded element.

In order to determine which of the stresses acting in the unidirectional layer are the most riskful, it is necessary to find the maximum of the following expressions entering into the Hill criterion:

$$
\max \left(\frac{\sigma_{1}}{X} ; \frac{\sigma_{2}}{Y} ; \frac{\tau_{12}}{S}\right)
$$

if the first fraction is maximum, then the most riskful are the normal stresses along the fibers, if the second one is maximum - then the riskful stresses act across the fibers, if the third one is maximum - then riskful stresses are tangential ones in the layer plane.

In the studied case:

For layer №1

$$
\begin{array}{ll}
\frac{\sigma_{1}}{X}=\frac{31.7}{1400}=2.3 \% ; & \frac{\sigma_{2}}{Y}=\frac{2.75}{93.1}=3 \% ; \\
\frac{\tau_{12}}{S}=\frac{1.42}{52.4}=2.7 \% ; &
\end{array}
$$

For layer №13

$$
\begin{aligned}
& \frac{\sigma_{1}}{X}=\frac{26.7}{1400}=1.9 \% \\
& \frac{\tau_{12}}{S}=\frac{1.32}{52.4}=2.5 \%
\end{aligned}
$$$$
\frac{\sigma_{2}}{Y}=\frac{-4.26}{-93.1}=4.5 \% \text {; }
$$

The analysis of the graphs and formulas (2) indicates that the prevailing stresses in the most stressed layers are the stresses across the fibers $\sigma_{2}$. In this regard, for a more favorable perception of the external loads field, it is recommended to add reinforcement in this direction.

\subsection{Modeling of spar loading with typical structures}

Other typical structures of the spar are considered, and their influence on its stressed state and deformation behavior are estimated.

The results of the finite element modeling of the considered structures are given below:

1. $\left(0^{\circ}\right)_{13}$ : deflection $U_{\mathrm{Y}}=2.16 \mathrm{~mm}$; twist angle $\varphi=7.08^{\circ} ; \quad R F_{\text {lay }=1}=20.5 ; \quad R F_{\text {lay }=13}=11.06$; $\sigma_{1}$ lay $=1=31.7 \mathrm{MPa} ; \quad \sigma_{1} \quad$ lay $=13=26.7 \mathrm{MPa} ;$ $\sigma_{2}$ lay $=1=2.8 \mathrm{MPa} ; \sigma_{2}$ lay $=13=-4.3 \mathrm{MPa} ;$ $\tau_{12 \text { lay }=1}=1.42 \mathrm{MPa} ; \tau_{12 \text { lay }=13}=1.32 \mathrm{MPa}$;

2. $\left(0^{\circ} / 90^{\circ}\right)_{3} / 0^{\circ} /(90 / 0)_{3}$ : deflection $U_{\mathrm{Y}}=3.53 \mathrm{~mm}$; twist angle $\varphi=9.19^{\circ} ; R F_{\text {lay }=13}=12.77 ; R F_{\text {lay }=12}=20$; $\sigma_{1}$ lay $=13=0.2 \mathrm{MPa} ; \quad \sigma_{1} \quad$ lay $=12=-14.5 \mathrm{MPa} ;$ $\sigma_{2}$ lay $=13_{13}=-1.7 \mathrm{MPa} ; \quad \sigma_{2}$ lay $=12=-0.2 \mathrm{MPa} ;$ $\tau_{12 \text { lay }=13}=3.2 \mathrm{MPa} ; \tau_{12 \text { lay }=12}=-2.3 \mathrm{MPa}$;

3. $\left(0^{\circ} / 45^{\circ} /-45^{\circ}\right)_{2} / 0^{\circ} /\left(-45^{\circ} / 45^{\circ} / 0^{\circ}\right)_{2}$ : deflection $U_{\mathrm{Y}}=2.98$ $\mathrm{mm}$; twist angle $\varphi=7.14^{\circ} ; \quad R F_{\text {lay }=12}=10.88$; $R F_{\text {lay }=11}=11.3 ; \sigma_{1_{\text {lay }}=12}=10.4 \mathrm{MPa} ; \sigma_{1 \text { lay }=11}=-13.6 \mathrm{MPa}$; $\sigma_{2} \quad$ lay $=12=-1.1 \mathrm{MPa} ; \quad \sigma_{2}$ lay $=11=0.5 \mathrm{MPa}$; $\tau_{12 \text { lay }=12}=-4.6 \mathrm{MPa} ; \tau_{12 \text { lay }=11}=4.2 \mathrm{MPa}$;

4. $\left(0^{\circ} / 45^{\circ} / 90^{\circ} /-45^{\circ}\right)_{3} / 0^{\circ}$ : deflection $U_{\mathrm{Y}}=3.34 \mathrm{~mm}$; twist angle $\varphi=7.50^{\circ} ; R F_{\text {lay }=1}=11.66 ; R F_{\text {lay }=5}=12.1$; $\sigma_{1} \quad$ lay $=1=-73.2 \mathrm{MPa} ; \quad \sigma_{1} \quad$ lay $=5=-70.8 \mathrm{MPa} ;$ $\sigma_{2}$ lay $=1=0.2 \mathrm{MPa} ; \quad \sigma_{2}$ lay $=5=-0.3 \mathrm{MPa}$; $\tau_{12 \text { lay }=1}=-0.47 \mathrm{MPa} ; \tau_{12 \text { lay }=5}=-0.2 \mathrm{MPa}$.

It is clear from the above-written that the most favorable structure for the spar from the viewpoint of ensuring the minimal deformations (both deflections and twisting of the free tip) is a unidirectional structure with the

parameters:

$\left(\left(0^{\circ}\right)_{n}, \varphi=7.08^{\circ}\right)$. From the standpoint of the stressed state risk, the most preferable structure is the mutually 
orthogonally reinforced structure $\left(0^{\circ} / 90^{\circ}\right)_{3} / 0^{\circ} /(90 / 0)_{3}$ $\left(R F_{\min }=12.77\right)$. In general, under the given loads, any structure satisfies the composite spar strength condition. The permissible safety factor for composite products $[\mathrm{RF}]$ $=2.0 \div 3.0$.

\section{Conclusion}

During the finite element modeling of the U-shaped composite wing spar on the basis of the carbon ribbon and the polyimide matrix, the main regularities of the spar stacking structure effect on its stressed state and elastic deformation behavior have been revealed.

The most favorable typical structure from the viewpoint of the load-bearing element rigidity is a unidirectional structure $\left(0^{\circ}\right)_{\mathrm{n}}$. However, from the standpoint of the stress state risk, the preferred structure is the one with $\left(0^{\circ} / 90^{\circ}\right)_{m} / 0^{\circ} /\left(0^{\circ} / 90^{\circ}\right)_{m}$. In general, the strength of the spar under the specified loads is ensured.

For more favorable perception the external loads field while maintaining high stiffness of the spar, it is recommended to establish $20-30 \%$ of layers reinforced at an angle of $90^{\circ}$ or close to it in the unidirectional structure.

\section{References}

1. R.M. Jones, Mechanics of Composite Materials (Taylor\&Francis, 1999)

2. V.S. Zhernakov, Y. S. Pervushin, P. V. Solovyev, Vestnik UGATU 19 №3 (69), 139-149 (2015)

3. Y.S. Pervushin, V.S. Zhernakov, Fundamentals of mechanics, design and manufacturing technology of items from layered composite materials: teaching guide (USATU, Ufa, 2008)

4. C. Herakovich, Non-elastic properties of composite materials (Mechanics, Moscow, 1978)

5. L. Brautman, R. Crock, Composite materials: Mechanics of composite materials (Mashinostroenie, Moscow, 1978) 